\title{
A influência do padrão de magreza para a mulher na contemporaneidade
}

\author{
The influence of standard of thinness for woman in the \\ contemporaneity
}

\section{Beatriz Ribeiro Cortez Cardozo Barata de Almeida Hessel', Izaura Maria Carvalho da Graça Furtado²}

\footnotetext{
'Autora para correspondência. Universidade Federal da Bahia. Salvador, Bahia, Brasil. ORCID: 0000-0002-1629-3392. bia_hessel@hotmail.com
} ${ }^{2}$ Faculdade Social da Bahia. Salvador, Bahia, Brasil. ORCID: 0000-0001-5740-7010.igfurtado@faculdadesocial.edu.br

\begin{abstract}
RESUMO | A presente investigação apresenta como tema central o padrão de magreza para a mulher na sociedade brasileira, sendo este o modelo de beleza hegemônico a ser seguido na contemporaneidade. Tem como objetivo compreender os fatores socioculturais contemporêneos que contribuem para que o padrão de magreza torne-se um instrumento de disciplinarização subjetiva sobre os corpos femininos. A metodologia empregada foi a revisão de literatura narrativa, de cunho qualitativo, com análise de contéudo temática. Os resultados encontraram a maneira como o gênero feminino é construído e como este participa do processo sociocultural de submissão ao ideal de beleza pesquisado. Também foi encontrado que à mulher é reservado um lugar de inferioridade em relação ao homem e foi questionado o conceito de saúde relacionado ao corpo gordo. Além disso, foi investigado como as práticas discursivas são mantenedoras do lugar social atribuído ao feminino e o papel da mídia hegemônica na construção e naturalização do padrão de magreza, ao utilizar o habitus e as representações sociais para esta finalidade. Deste modo, concluiu-se que a mídia hegemônica contribui para a reafirmação do lugar de submissão da mulher e da imposição do padrão de magreza à ela, por meio do agenciamento dos desejos femininos. A alimentação, neste contexto, torna-se restritiva para que a mulher alcance este ideal de beleza e se purifique de seus pecados. Com este estudo, espera-se contribuir com os estudos de gênero, ampliando ainda mais esta área de pesquisa.
\end{abstract}

PALAVRAS-CHAVE: Controle do peso. Saúde da mulher. Representação social.

\begin{abstract}
The present investigation introduce as central theme the standard of thinness for woman in the Brazilian society, what is the main model of beauty to be followed in contemporaneity. Has as aim to understand the social and cultural factors which contributes for the standard thinness become a instrument of subjective discipline on the female gender bodies. The methodology employed was the narrative literature review, of qualitative stamp and thematic content analysis. The results founded referred to the mode of construction of the female gender and how it participates in the social and cultural process of submission to the ideal of beauty researched. Also was founded that to the woman is reserved a place of inferiority compared to man and was questioned the health concept toward to the fat body. Besides that, was investigated how the discursive practices maintain the social place attributed to the feminine and the role of hegemonic media in the construction and naturalization of the standard of thinness, using the habitus and social representations for this purpose. In this way, it was concluded that the hegemonic media contributes to reaffirmation of the female place of submission and for the imposition of the thinness standard to her, by means of the agencyment of the feminine desires. The feeding act, in this context, becomes restrictive for the woman obtain this beauty ideal and for purify yourself of your sins. With this study, it is expected to contribute to gender studies, further expanding this area of research.
\end{abstract}

KEYWORDS: Weight control. Woman's health. Social representation. 


\section{Introdução}

A temática do trabalho surge com a ampla frequência de notícias e imagens divulgadas pela publicidade hegemônica na atualidade, que valorizam a magreza como ideal de beleza e os sacrifícios exercidos pelas mulheres para encaixar-se neste ideal de corpo. A mulher pode sentir-se impelida à seguí-lo, o que se torna uma forte imporsição em seu dia a dia. Sendo assim, delimita-se como problema de pesquisa quais os fatores socioculturais na contemporaneidade que contribuem para que $\circ$ padrão de magreza torne-se um instrumento de controle subjetivo sobre a mulher.

O presente trabalho considera o contexto em que a mulher está inserida e como este influencia sua subjetividade e comportamentos, colocando enfoque na constituição social e cultural do padrão de magreza feminino e buscando compreender como a construção do gênero feminino ocorre neste contexto.

É proposto como objetivo geral compreender os fatores socioculturais na contemporaneidade que tornam o padrão de magreza um instrumento de controle subjetivo sobre a mulher, enquanto os objetivos específicos buscam identificar como o machismo objetifica o corpo feminino, analisar como a mídia hegemônica influencia a mulher a seguir o ideal de corpo magro, e compreender de que modo a cultura ocidental contribui para a submissão da mulher através da validação do padrão de magreza.

Importantes conceitos para o conhecimento da temática são abordados, como gênero na perspectiva sociocultural; habitus, trabalhado por Pierre Bourdieu (2012), e de que maneira este participa da constituição das Representações Sociais (Jodelet, 2001; Moscovici, 2003) acerca do lugar social da mulher na contemporaneidade. Este é formado por bases patriarcais, machistas e misóginas (Spivak, 2010). Também são trazidos os estudos de Joan Scott (1995), Simone de Beauvoir (1967) e Judith Butler (2016) e como são construídos os lugares sociais do discurso, segundo Foucault (2008). Trata, ainda, sobre como a mídia hegemônica utiliza as Representações Sociais com o intuito de manter o lugar de submissão da mulher e do padrão de magreza reservado à ela (Memória, 2012; Freitas, 2002; Almeida, 2015).
O termo Gênero é analisado por Joan Scott (1995) como uma categoria que é imposta socialmente sobre um corpo, além de ser o local primário onde - poder é articulado e significado, fortalecendo as relações de poder do gênero masculino sobre - feminino. É também uma categoria de análise e pesquisa social a qual não implica em ameaça ao gênero masculino, já que inclui o feminino mas não cede lugar integralmente ao termo "mulheres". A constituição dos gêneros masculino e feminino ocorre de maneira relacional, onde um interfere na construção no outro. Neste trabalho, portanto, gênero é conceituado enquanto construção social, histórica, cultural, política e discursiva.

Complementando Scott, Judith Butler (2010 como citado em Sene, 2017) propõe que o gênero masculino é considerado universal e, portanto, enaltecido diante do gênero feminino, o qual é definido com base nos regulamentos e normas impostas pelos homens. Por isso, os gêneros se constituem dentro das relações de poder e são causados por elas (Sene, 2017).

As representações sociais também influenciam a constituição dos gêneros. Como afirma Lauretis (1994 como citado em Mourão, 2012), o gênero também é definido como representação e como autorrepresentação, sendo resultado de tecnologias sociais como o cinema e a publicidade, e de discursos e práticas institucionalizadas e do senso comum.

Deste modo, as representações sociais são conceituadas no presente estudo de acordo com as definições de Serge Moscovici (1961/1976 como citado em Moscovici, 2003; 1976 como citado em Moscovici, 2003; 1981 como citado em Oliveira \& Werba, 2013) e Denise Jodelet (2001), como - conjunto de conceitos, práticas, ideias e valores que surgem na vida cotidiana. São conhecimentos do senso comum que circulam e se cristalizam por meio de todos os tipos de relações humanas, através dos discursos, gestos e práticas existentes, sendo presente em todos os âmbitos da vida. Originam-se nas relações sociais e as influenciam por meio de sua organização e orientação, contribuindo para a construção da realidade social, das identidades individuais e sociais, do desenvolvimento das pessoas, dos coletivos e das transformações da sociedade. 
A relevância do trabalho justifica-se com as pesquisas realizadas nos bancos de dados, que mostraram que a contituição social do padrão de magreza e sua relação com o controle do corpo feminino ainda não é um tema explorado em quantidade considerável, possuindo uma produção acadêmica incipiente. Além disso, grande parte dos trabalhos encontrados apresentavam um maior viés para as patologias relacionadas à magreza, como a anorexia e a bulimia. A presente pesquisa trata o ideal de magreza como uma normatização sobre o corpo da mulher, procurando elucidar os principais fatores socioculturais que contribuem para esse processo. Pretende contribuir com uma reflexão crítica quanto ao controle dos corpos da população feminina, bem como o seu sofrimento nesse processo. Assim, o trabalho poderá fortalecer as vertentes feministas, 0 empoderamento feminino e a autovalorização das mulheres sobre seus corpos, aceitando-os da maneira que são e questionando este padrão de beleza que pode gerar danos à sua subjetividade e qualidade de vida.

\section{Metodologia}

Para a construção da pesquisa, foi realizada uma pesquisa descritiva, de cunho qualitativo e análise bibliográfica narrativa. A revisão de literatura narrativa (Rother, 2007) permite a constituição de relações com pesquisas já construídas, a formulação de novas perspectivas sobre o tema e, consequentemente, o fortalecimento da área do conhecimento a qual ela pertence, segundo a Universidade Estadual Paulista [Unesp] (2015).

Apresenta cunho qualitativo porque foi considerada a relação do meio social com o sujeito de pesquisa, ou seja, a mulher na relação com o padrão ideal de corpo. Focou em aspectos qualitativos da literatura, fazendo uma análise qualitativa do conteudo e sintetizando os resultados encontrados sem uma análise estatística (Shaughnessy, Zechmeister \& Zechmeister, 2012).

Os dados foram coletados em artigos, livros, vídeos, periódicos e dissertações de mestrado por meio do banco de teses e dissertações da Capes e dos portais eletrônicos BVS-Psi, SciELO e Repositório
Institucional da Ufba (NEIM), sendo utilizadas as palavras-chave seguintes: mulher, construção do gênero feminino, padrão de magreza, corpo feminino, ideal de beleza, machismo, mídia hegemônica, lugar do feminino e objetificação da mulher, cada termo separadamente e em conjunto.

Foram encontradas e utilizadas dezeseis obras relacionadas ao tema em questão. $O$ critério de seleção dos materiais priorizou trabalhos que mais se relacionaram com os objetivos da pesquisa, bem como buscou enfatizar obras e textos de autoras/es com papel fundamental nos estudos de Gênero. Além disso, foi dada preferência pela leitura reflexiva de obras de autoras mulheres como forma de valorizar o lugar de fala delas sobre o tema em questão. Assim, procurou-se estabelecer uma relação entre estas leituras e o padrão de corpo da atualidade, relacionando-os à construção social do gênero feminino.

Na análise de conteúdo (Shaughnessy et al., 2012), as categorias temáticas delimitaram-se em discussões da literatura sobre o padrão de magreza para a mulher jovem, a construção sociocultural do gênero feminino, o machismo como contribuinte para $\circ$ seguimento deste padrão de beleza, assim como o papel da mídia hegemônica e do capitalismo para o incentivo a este seguimento. A análise do material priorizou obter respostas quanto aos objetivos e problema de pesquisa.

\section{Resultados e Discussão}

A partir da leitura dos textos selecionados, é possível refletir quanto à construção da autoimagem da mulher e de seus processos de subjetivação, no que concerne à influência social e cultural nos ideais de beleza. Sobre isso, Pierre Bourdieu (2012) afirma que a perspectiva androcêntrica é a visão de mundo por meio da qual ocorrem a divisão e a classificação social dos corpos dos gêneros feminino e masculino. Esta divisão e classificação simbólicas ocorrem a partir de teorias, práticas e socializações difusas porém permanentes nos grupos sociais e na vida cotidiana, instituindo um uso diferencial dos corpos de gêneros tidos como opostos. Isto influencia a constituição do habitus, que se encarna nos corpos e atos dos individuos e os auxiliam a assumir a visão 
de mundo androcêntrica, advinda da cultura machista e patriarcal. Assim, se constituem as relações sociais de dominação do gênero masculino sobre o feminino.

O habitus foi encontrado como um dos fatores socioculturais que contribuem para a construção do corpo da mulher. Ele manifesta-se no corpo e age de maneira automática, sem um agente específico pois é difuso e se submete às normas sociais já impostas e delimitadas de acordo com o princípio androcêntrico, instaurando lugares, espaços e atividades distintas às mulheres, de cunho inferior em relação aos aspectos delimitados para os homens.

O autor afirma que a representação social do corpo feminino gera influências no olhar do outro e na autoimagem da mulher, tornando-se reações sociais ao binarismo feminino e masculino. $O$ indivíduo introjeta a representação, que é construída socialmente, e esta irá influenciar seu corpo e comportamentos, que são particulares. Como o habitus é construído no âmbito sociocultural, assim como as representações sociais, percebe-se que $\circ$ primeiro participa da construção do segundo, sendo ambos influenciados pelos pressupostos do machismo, patriarcado e androcentrismo que constituem a sociedade na atualidade.

Consequentemente, os dois fenômenos participam da construção da autoimagem dos indivíduos, sobretudo das mulheres que seguem o padrão de magreza. Bourdieu (2012) ainda elucida os aspectos associados a cada gênero do modelo binário heteronormativo, onde ao masculino são associados aspectos de agilidade, agressividade, virilidade, rigidez, atividade e vida pública; entretanto, ao feminino são relacionados aspectos de passividade, cuidado, leveza, vida privada, simpatia, disponibilidade, receptividade, submissão, discrição, apagamento e beleza. Sendo assim, o ideal de beleza está incluído.

Como os gêneros são construídos de modo relacional (Scott, 1995), Bourdieu (2012) afirma que a muIher é vista como um ser de falta, uma existência negativa porque ela é tudo o que o homem não é, ou seja, à ela são atribuídas características opostas e ausentes nos homens, sendo ele um modelo universal para a elaboração destes aspectos que são associados à cada gênero, como afirmou Butler (2016).
As mulheres se mantêm em uma perspectiva de insegurança corporal, pois elas "existem primeiro pelo, e para, o olhar dos outros" (Bourdieu, 2012, p. 82). É possível que as mulheres introjetem esta verdade através das representações sociais e do habitus, reproduzindo-a em seus comportamentos e crenças e na relação com outras mulheres, influenciando-as negativamente. Elas podem acreditar que são inferiores e submissas às vontades e desejos dos homens e que seus corpos não estão ou serão bonitos o suficiente para agradá-los (Beauvoir, 1967; Bourdieu, 2012 ).

Outra questão relevante presente na literatura foi a costrução da feminilidade. Simone de Beauvoir (1967) relata que ela, construída com base nas expectativas sociais, está intrinsecamente associada à impotência, docilidade e futilidade, ao enfeitar - corpo e reprimir a espontaneidade para agir com graça, sutileza e encanto. Ser autoconfiante e empoderada diminui a feminilidade da mulher e, consequentemente, sua potência de sedução direcionada aos homens. Quanto à espontaneidade, percebe-se que esta característica faz referência a vários setores da vida cotidiana da mulher, tanto o comportamental e de suas vestes quanto o próprio alimentar-se, onde muitas delas passam a controlar e agenciar seus desejos, chegando a calcular a quantidade de calorias de cada refeição consumida no intuito de alcançar o ideal da magreza.

Complementando Beauvoir (1967), Gayatri Chakravorty Spivak (2010), filósofa e feminista indiana, afirma que a mulher possui o lugar de objeto na sociedade atual e não de sujeito, o que é atribuído aos homens. Mantendo-a neste lugar, como por meio do incentivo e valorização de sua submissão ao padrão de corpo ideal, mantém-se também o modelo de sociedade patriarcal e machista, com as relações de poder do gênero masculino sobre - feminino prevalecendo. É possível que um dos grandes incômodos sociais gerados pelo movimento Feminista seja este: possibilitar que as mulheres ocupem um lugar de questionamento social, colocando em risco as relações de dominação dos homens sobre as mulheres.

Spivak (2010) afirma que é fornecido à existencia feminina o lugar do différend, ou seja, o lugar da inacessibilidade do discurso e da desvalorização da perspectiva feminina sobre as questões sociais e 
individuais. Portanto, é esperado que a mulher ocupe - lugar de submissão às normas sociais e de gênero, estabelecidas pela visão de mundo androcêntrica e machista. Por meio das representações sociais e do habitus, a mulher passa, mais uma vez, a apreender que seu lugar deve ser o da inferioridade, 0 da não-voz e não-escuta. O lugar de objeto, como afirma a filósofa.

O conceito de precariedade, de Judith Butler (2016), pode ser relacionado ao lugar de inferioridade antes mencionado. A precariedade elucida 0 lugar da mulher na sociedade atual, sendo definido como uma condição social e política a qual determinadas populações sofrem mais em decorrência de redes de apoio social e econômico que são enfraquecidas e insuficientes, consequentemente submetendo as mulheres, com mais frequência do que aos homens, à violências de diversas formas, injúrias e até mesmo morte.

Butler (2016) questiona por que alguns corpos são mais reconhecidos do que outros na esfera da aparência, explanando sobre o fato de que as normas sexuais e de gênero delimitam quais corpos serão ou não legíveis neste contexto. Estas normas são construídas no interior da perspectiva patriarcal, machista e misógena e delimitadas pelo contexto social, histório e cultural. São expressadas nos corpos e em suas práticas de constituição de gênero e de vivências das sexualidades, e as pessoas que não se encaixam nelas, como as que não pertencem ao ideal de corpo magro, estão mais susceptíveis à sofrerem violências sociais. Há, como exemplo, o fenômeno da gordofobia o qual se configura como um intenso gerador de sofrimento psíquico e físico na vida de pessoas gordas.

Outro aspecto que merece destaque e relacionase com a construção do corpo feminino, exposto na literatura, é a discussão sobre as Modalidades Enunciativas ou do Discurso, de Foucault (2008). Estas delimitam os lugares dos indivíduos que discursam na rede de poder, sendo eles: quem fala, de onde fala, porque fala e para quem fala. O discurso, para o sociólogo, sempre é constituído nas relações sociais e, portanto, se relaciona aos lugares sociais das mulheres e da mídia hegemônica na atualidade, a qual valoriza o ideal de corpo magro.
O discurso é formado por diversas instâncias como a fala, os atos, a escrita, as imagens, as práticas individuais e sociais e até mesmo as conversas cotidianas (Almeida, 2015; USP, 2017). Sendo assim, as imagens da mídia hegemônica participam da rede dos discursos. Para Almeida (2015), o discurso deve ser pensado para que haja reflexão em como são constituídas as representações sociais dos indivíduos.

O relevante no discurso é sua forma e não seu conteúdo. Assim, o mais importante é o lugar de fala do emissor e não o sentido de seu discurso. Este lugar é o formador das relações de poder entre os indivíduos pois gera hierarquizações entre eles. $O$ discurso também produz verdades e estas participam da qualidade de vida ou da ausência desta para os sujeitos (Foucault, 2008).

A partir dessa perspectiva, pode-se pensar sobre o lugar do discurso médico na relação com a pessoa gorda, onde, na maioria das vezes, ela é patologizada e medicalizada em nome da saúde. Enquanto isso, o médico ocupa o lugar de detentor da verdade sobre o corpo do outro no contexto social das relações de poder (Foucault, 2008). Estes fatores podem contribuir para a valorização do ideal de magreza na atualidade, contexto no qual o corpo gordo é relacionado à doenças e a um indesejável modo de ser, reiterado pelo discurso médico e pelo senso comum. A forma do discurso pode ser compreendida também como o modo de ser, de se vestir e a representação social que cada sujeito possui. Pessoas que têm corpos que se encaixam ao ideal de beleza provavelmente têm seus discursos e verdades validadas com maior frequência por seu meio social do que as pessoas que se diferenciam deste modelo.

Também foi encontrado como resultado que a mídia hegemônica é um dos principais meios de produção de discursos com o objetivo de manter as mulheres no agenciamento de seus desejos e no controle de seus corpos para permanecerem dentro do ideal de corpo valorizado e para que seja possível naturalizar este modelo de beleza. Além disso, para preservar os lucros da indústria cosmética. Isso ocorre pois as tentativas em manter-se magra são rodeadas por rituais, como dietas, cirurgias plásticas, excesso de idas à academia para manutenção dos exercícios físicos, dentre outros métodos. 
A autora Memória (2012), analisando o papel da mídia hegemônica na relação das mulheres com o ideal de beleza vigente, afirma que a publicidade hegemônica na contemporaneidade mostra os valores sociais existentes e os que surgirão num futuro próximo, apresentando às mulheres expectadoras modos de sentirem-se felizes, amadas, reconhecidas e realizadas. Isso justifica-se pois a mídia associa a obtenção de determinados produtos cosméticos à realização dos desejos femininos, à felicidade, alegria e realização pessoal, como se os produtos pudessem trazer estas qualidades à vida das mulheres. Busca também favorecer o consumo dos produtos divulgados nas imagens publicitárias através da identificação das mulheres expectadoras com as modelos, pois a mídia hegemônica traz os valores culturais nestas imagens e os associa às modelos. Desta maneira, os comportamentos das mulheres são influenciados pelos atos das modelos devido às representações sociais, que detêm os valores culturais divulgados. Isso, consequentemente, participa do processo de socialização feminina e, portanto, a identificação é facilitada.

A autora afirma que os corpos fotografados pela publicidade hegemônica possibilitam a transmissão de códigos culturais, habitus da sociedade contemporânea, tornando-se mecanismos de interação social e de favorecimento ao surgimento de comportamentos nas expectadoras, como $\circ$ do consumo. Ainda, a imagem representa algo que está ausente no presente. Ela promove e circula as representações sociais, condicionando modos de ser e estar no mundo, possibilitando o surgimento de novas representações sociais e cristalizando habitus na conduta social. A mídia hegemônica pode, então, incentivar as mulheres a seguirem o padrão de beleza, já que suas modelos possuem, em grande parte, corpos que se encaixam ao ideal de corpo magro da atualidade.

No contexto sociohistórico do surgimento da mídia hegemônica, até a década de 1950 as mulheres buscavam alcançar ao máximo o ideal de beleza da época, com a intenção de adquirir posição social e casamentos, por estarem incluídas em uma sociedade patriarcal, machista e misógina que influenciava seu modo de viver. Neste período, a publicidade midiática se apropriou da imagem e das representações sociais femininas, divulgando-as de avental e sujas devido ao trabalho doméstico. Já na década de 1960, com a ascensão do movimento feminista, a mídia hegemônica começou a divulgar a imagem feminina sempre limpa com a finalidade de mostrar o potencial dos produtos comercializados que poderiam deixá-la com maior comodidade e praticidade em sua vida diária.

O movimento Feminista surge com o objetivo de encerrar as relações de poder do gênero masculino sobre o feminino e de promover a igualdade entre ambos, emergindo no mundo ocidental em um período de diversas denúncias às opressões diárias vivenciadas, apresentadas por movimentos libertários (Mourão, 2012). Questionou, dentre outros aspectos, a construção social dos papeis de gênero e a submissão feminina ao patriarcado e ao machismo. A mulher passa a não se interessar mais em atender às demandas e expectativas do olhar masculino e sim em atender à suas próprias expectativas, incluindo sua imagem corporal (Memória, 2012).

Deste modo, a publicidade hegemônica renova a divulgação da imagem feminina, relacionando-a à realização e ao prazer originados em seu autocuidado, com a utilização de produtos cosméticos de forma recorrente e com a imposição da beleza que the segue em todo e qualquer lugar, promovendo culto e cuidados contínuos ao corpo, segundo a autora.

Enquanto 0 movimento Feminista questiona os mecanismos disciplinares sobre a sexualidade e o corpo feminino, favorecendo a autonomia das mulheres quanto ao seu próprio corpo (Amaral, 2008), simultaneamente o mercado capitalista se apropria deste discurso para, então, conseguir lucros com o aumento do consumo da indústria da beleza, a qual é relacionada ao autocuidado corporal pela mídia hegemônica. Surge uma submissão feminina ao padrão de beleza imposto pela sociedade, reiterada pelo habitus e pelas representações sociais divulgadas por esse tipo de publicidade. A mulher passa a vivenciar um novo modo de agenciamento dos seus desejos, sendo exercido por si mesma, e passa a sentir a necessidade em ser e manter-se magra para pertencer aos ideais do mercado capitalista (Memória, 2012).

Este agenciamento é um poder fluido porém danoso e controlador em seu dia a dia, e o algoz não possui 
um rosto específico, como o do marido (na época anterior ao surgimento do Feminismo). $O$ algoz é constituído pela mídia hegemônica que aparece em todo lugar, de maneira difusa.

Na atualidade o corpo real é negado e o corpo magro é idealizado, tornando-se um modelo a ser seguido. Para Memória (2012), as imagens da publicidade hegemônica mostram semelhanças entre os corpos das modelos, sempre magras, com rostos cuja pele transmite a sensação de ser plástica, sem nenhum tipo de mancha, e com as poses corporais e roupas também parecidas entre si. Isto denota a busca pelo estereótipo da magreza e pelo encaixe das mulheres expectadoras e das modelos nos ideais de padrão corporal, gerando padronização e disciplinarização dos corpos femininos.

Seguir o estereótipo da magreza resulta no apagamento das singularidades da aparência das muIheres, apagamento este já discutido por Bourdieu (2012), e no controle do corpo feminino. Este controle é expresso no incentivo do consumo de dietas restritivas, no excesso de cirurgias estéticas, de atividades físicas e no uso de cosméticos da indústria da beleza, gerando submissão e obediência aos pressupostos do mercado capitalista, que se interessa por lucros e, a cada dia, elabora métodos como estes para atender sua demanda de mercado (Memória, 2012 ). Portanto, são produzidos diversos efeitos na vida das mulheres, o que implica em sua qualidade de vida e bem-estar, sobretudo sobre sua percepção de autovalor enquanto uma pessoa única e um sujeito social.

As cobranças pelo corpo ideal feminino permanecem e são cada vez mais elevadas, e a tecnologia atua a este favor. Com o intuito de manter o controle dos corpos e subjetividades femininas e as relações de poder, a mídia hegemônica manipula as imagens publicitárias por meio de tecnologias disponíveis na atualidade, como programas de computador que alteram o aspecto físico dos corpos e rostos das modelos para incluí-los na expectativa do ideal de beleza. Contribuem também para tornar os corpos das modelos semelhantes entre si e excluir qualquer característica que os diferencie ou que seja considerado um defeito. A mídia hegemônica consegue, então, mostrar corpos femininos perfeitos, limpos e sem defeito algum (Memória, 2012).
Outro resultado encontrado quanto ao padrão de magreza é o controle feminino sobre a alimentação. Freitas (2002) afirma que a supervalorização do corpo ideal, pela sociedade como um todo e pelos indivíduos, relaciona o peso corporal às conquistas sociais, impondo que a individualidade do corpo precisa ser cuidada para o mundo. Assim, a experiência subjetiva de viver em um corpo físico voltase às expectativas do olhar universal da sociedade, tendo como imposição a satisfação do olhar social e não da própria mulher. Ela é induzida socialmente, por meio das representações sociais e do habitus transmitidos pela mídia hegemônica, a atender às normas sociais já estabelecidas quanto à sua aparência, desvinculando-se das possibilidades do seu corpo real e único, numa tentativa em corresponder a uma demanda social.

Freitas (2002) afirma que o controle exercido pelas dietas restritivas na contemporaneidade, mesmo sendo uma prática sacrificante, torna-se uma necessidade para alcançar o corpo ideal. A mulher passa a negligenciar a introdução de alimentos saudáveis na dieta cotidiana e a privar-se de alimentos em geral para consumir shakes vendidos facilmente em farmácias e divulgados em propagandas, ou utilizar-se de inibidores de apetite. Muitas vezes, podem tornar-se anoréxicas e/ou bulímicas, dentre tantos outros transtornos alimentares existentes, em nome do ideal de magreza. Nesta perspectiva, considerando que o discurso médico afirma como verdade a gordura sendo patogênica, e o discurso midiático reitera que a magreza traz felicidade, como as mulheres podem se sentir neste contexto? É possível compreender como seu bem-estar e qualidade de vida são dificultados.

A mídia hegemônica vende esta verdade e afirma que participar do mercado capitalista por meio do corpo extremamente magro fornece uma identidade sedutora e atrativa à mulher. Para a interpretação social, a magreza transmite uma mensagem de leveza, limpeza e pureza em relação à subjetividade da mulher, como se ela fosse ausente de pecados. Na contemporaneidade, ser light significa ter uma existência leve e saudável, no que tange ao corpo físico, aos alimentos ingeridos e ao estilo de vida diário. Para alcançar uma imagem de inocência e fragilidade, se distanciando da tensão da vida contemporânea, as mulheres buscam a leveza 
física como forma de obter a leveza subjetiva, a limpeza e a ausência do peso de qualquer pecado, como afirma a autora.

Esta representação social influencia o significado dos corpos, onde a magreza corresponde a uma existência bela e angelical, pura, indicando bondade de caráter e sentimentos brandos, enquanto o corpo gordo recebe um significado oposto para a interpretação social. Por isso, quanto mais magreza o corpo expressar, mais será relacionado à qualidades positivas.

autocontrole dos corpos femininos se expressa no receio em engordar e na reidentificação e conformidade da mulher com o mundo que a segrega e a padroniza. Essa disciplinarização dos corpos indica que o corpo magro participa do mercado capitalista, enquanto o corpo gordo, não. Fazer parte do mercado capitalista relaciona-se não somente ao consumo dos produtos da indústria da beleza, mas também ao autovalor da mulher, que é moldado e influenciado pelos valores e crenças que constituem as representações sociais, presentes das imagens midiáticas que servem à potencilização dos lucros capitalistas.

Assim, a mulher light cumpre cotidianamente as normas sociais que disciplinam e padronizam seu corpo, com o custo de reprimir sua própria vontade sobre sua alimentação, seu modo de se vestir, sua maneira de comportar-se e sua espontaneidade. Portanto, seu modo de ser e existir no mundo que a circunda. Neste contexto, a reflexão feminina quanto à temática é extremamente necessária: seguir o estilo de vida magro vale realmente os sacrifícios?

Para Freitas (2002), este modo de experienciar a vida é repressivo e danoso para a mulher. Adequarse a ele coloca a mulher no lugar de prisioneira, e o mais agravante é que ela se torna prisioneira de si mesma. Portanto, é necessário questionar até quanto ser magra na atualidade corresponde ao ser saudável ou a ter uma subjetividade feminina fortalecida.

Deste modo, o agenciamento dos desejos exercido pelas mulheres foi fortalecido pela indústria cosmética, que passou a ter maior poder de influência na atualidade, organizando rituais obrigatórios de cuidados à beleza a serem cumpridos com a justificativa da mulher estar fornecendo a si mesma mais amor, valorização e estima. A perfeição funciona como um dos pilares da indústria da beleza, empregada de forma subliminar nas propagandas e imagens divulgadas pela mídia hegemônica. Entretanto, como a perfeição é alcançada na publicidade por meio do uso de tecnologias, como programas de computador, ela nunca poderá ser alcançada na realidade das mulheres sem estes artifícios. A mídia hegemônica, então, vende um habitus impossível de ser conseguido na concretude, pois o consumo dos produtos da indústria da beleza não é suficiente para chegar à perfeição destas imagens manipuladas digitalmente (Memória, 2012).

Este processo contribui ainda mais para a insegurança corporal das mulheres, e consequentemente, para o estabelecimento da desvalorização de si mesma, já que o amor próprio é relacionado à quantidade de perfeição que o corpo feminino consegue obter e performar.

Além disso, os riscos dos procedimentos estéticos são ignorados socialmente. Seus incômodos, dores, efeitos adversos e possíveis deformações decorrentes são menosprezados. $O$ pós-operatório das cirurgias estéticas, assim como de qualquer outro tipo de intervenção cirúrgica, é extremamente doloroso e pode ocasionar problemas futuros se não ocorrer da maneira adequada ou se houver complicações de saúde. Mesmo assim, a cirurgia estética é bastante incentivada socialmente e pelo discurso médico, mais uma vez demonstrando a fragilidade das verdades que estes discursos produzem. Isso denota relações de poder da medicina (Foucault, 2008), da mídia hegemônica (Memória, 2012) e do capitalismo para com os indivíduos.

Assim, a imposição do corpo perfeito é colocada em maior parte sobre as mulheres (Freitas, 2002; Almeida, 2015). Almeida (2015) relata que os valores das representações sociais são transmitidos para elas nos momentos em que menos se espera, os momentos de lazer, como na leitura de um romance e no contato com músicas e programas de televisão. Deste modo, as mulheres encontram-se destituídas de criticidade quando se deparam com os valores sociais empregados e a repetição das normatizações são interiorizadas como verdades. Esta estratégia da mídia hegemônica dificulta o 
enfrentamento das mulheres nestas situações, contribuindo para a naturalização e assimilação destes valores.

\section{Considerações Finais}

Por meio da literatura levantada, foi encontrado que o habitus é influenciado pela cultura patriarcal e machista, participando da constituição dos aspectos dos gêneros feminino e masculino. Ao masculino são associadas características como rigidez, atividade e força, enquanto ao feminino são reservadas a passividade, simpatia, discrição, submissão e apagamento. A mulher é um sujeito de falta diante do homem, pois ela apresenta as características que ele não possui, num contexto em que o homem é considerado o modelo universal de parâmetro para a delimitação dos aspectos do gênero feminino.

Além disso, o habitus participa das representações sociais e fortalece as relações de poder dos homens sobre as mulheres. Consequentemente, à mulher é reservado o lugar social de submissão, em comparação ao lugar social do homem.

O padrão de magreza surge num contexto de mudança de perspectiva social, no qual antes a mulher se submetia às expectativas do olhar masculino $e$, após o surgimento do movimento Feminista na década de 1960, passa a não agir mais deste modo. Contudo, surge um poder fluido de agenciamento de seus desejos, incentivado pelo mercado capitalista. Um poder exercido sobre si mesma e sobre suas práticas corporais de alimentação, que se torna restritiva e light, e incentiva 0 excesso de atividades físicas e de cirurgias plásticas, negligenciando os riscos do pós-operatório destas.

Neste contexto, o autocontrole sobre seu próprio corpo torna-se claro e a disciplinarização e padronização dos corpos femininos também. Distanciar-se do ideal de beleza magro recebe a interpretação social e médica de se estar doente caso torne-se gorda, ou fora do mercado de consumo, podendo fazer com que a mulher se sinta insegura quanto a sua imagem corporal.
Também foi encontrado que o lugar de submissão feminina instituído socialmente mantém os modos de socialização machistas e patriarcais, impedindo que a mulher produza discursos validados. $O$ discurso social naturaliza o padrão de magreza. $O$ discurso do senso comum, transmitido pela mídia hegemônica, e o discurso médico podem medicalizar e patologizar os corpos destoantes do ideal de magreza, sendo importante questionar que lugar a saúde ocupa nesta perspectiva e se a definição de saúde como ausência de gordura corresponde à realidade.

Um importante resultado encontrado foi que $a$ indústria da beleza, que lucra com o consumo excessivo de cosméticos, dietas restritivas, academias de exercícios físicos e cirurgias estéticas, transmite as representações sociais e o habitus por meio das propagandas e imagens divulgadas pela mídia hegemônica. Portanto, estes fenômenos contribuem para o seguimento do padrão de magreza pelas mulheres, o que é ainda mais comprometido pois a mídia hegemônica atua nos momentos femininos de lazer. Isso dificulta que a mulher utilize seu senso crítico, por serem momentos onde não se espera precisar fazê-lo.

A mídia hegemônica utiliza as representações sociais para criar uma identificação das modelos mostradas com as mulheres expectadoras. As mulheres, então, tornam-se potencialmente maiores consumidoras dos produtos divulgados neste tipo de mídia. O mercado capitalista lucra com a manipulação da subjetividade feminina, associando autoestima e autovalorização à quantidade de consumo dos produtos da indústria da beleza.

Sendo assim, o problema e objetivos da presente pesquisa foram respondidos de forma satisfatória. A saúde passa a ser um conceito aqui questionado, pois patologizar o corpo gordo apenas por compará-lo com o corpo magro termina por ser injusto. Considera-se a importância da despatologização do corpo gordo e a valorização dos corpos, independente da forma que possuem, pois um corpo saudável é o que possibilita a liberdade de escolher e vivenciar as experiências pessoais e sociais com qualidade. 
Foi evidenciado o quanto a mídia hegemônica se utiliza do lugar socialmente atribuído à mulher no intuito de produzir lucros, já que a indústria da beleza direciona seus produtos para o público feminino por saber que as mulheres sentirão necessidade em comprá-los para se adequarem ao ideal de beleza, o que faz parte do agenciamento dos desejos.

As limitações encontradas constaram não ser possível investigar, devido ao recorte metodológico, questões encontradas na literatura pesquisada como os conceitos de violência simbólica, trabalhado por Pierre Bourdieu, e biopoder e biopolítica, trazidos por Michel Foucault. Pesquisas futuras podem utilizá-los, relacionando-os à temática do padrão de magreza. Como o estudo limitou-se a uma análise da literatura, sugere-se que pesquisas futuras realizem um trabalho de campo com as mulheres quanto a esta temática, já que as contribuições de pesquisas sobre este assunto não devem se encerrar aqui.

A presente pesquisa pretende contribuir com a reflexão feminina sobre o tema, contribuindo para a qualidade de vida das mulheres, e com a lacuna científica encontrada, enriquecendo os estudos sobre gênero e psicologia.

\section{Contribuições dos autores}

Hessel, B. R. C. C. B. A. participou da concepção, delineamento, busca e análise dos dados da pesquisa, interpretação dos resultados e redação do artigo científico. Furtado, I. M. C. G. participou da concepção, delineamento e busca dos dados da pesquisa.

\section{Conflitos de interesses}

Nenhum conflito financeiro, legal ou político envolvendo terceiros (governo, empresas e fundações privadas, etc.) foi declarado para nenhum aspecto do trabalho submetido (incluindo mas não limitandose a subvenções e financiamentos, conselho consultivo, desenho de estudo, preparação de manuscrito, análise estatística, etc.).

\section{Referências}

Almeida, A. (2015). Velhas Histórias, Novas Leituras: a bela do século XXI. In: A. Almeida, \& I. Alves. (Org.). Mulheres em Seriados: configurações. Salvador: EDUFBA/NEIM/CNPq.
Amaral, M. (2008). O Fenômeno do Culto ao Corpo Moderno e a Magreza como Símbolo de Beleza: estudo sobre o movimento "Pró-Ana" no Brasil. Congresso Português de Sociologia, Lisboa, Portugal. 6. Recuperado de http://historico.aps.pt/vicongresso/pdfs/242.pdf

Beauvoir, S. (1967). O Segundo Sexo II: a experiência vivida (2a ed.). São Paulo: Difusão Européia do Livro.

Bourdieu, P. (2012). A dominação masculina (1 1 a ed.). Rio de Janeiro: Bertrand Brasil.

Butler, J. (2016). Corpos que ainda importam. In: L. Colling (Org.). Dissidências Sexuais e de Gênero. Salvador: EDUFBA.

Foucault, M. (2008). A Arqueologia do Saber (7a ed.). Rio de Janeiro: Forense Universitária.

Freitas, M. C. S. (2002). Mulher Light: Corpo, Dieta e Repressão. In: S. L. Ferreira, \& E. R. Nascimento (Org.). Imagens da Mulher na Cultura Contemporânea. Salvador: NEIM/UFBA.

Jodelet, D. (2001). As Representações Sociais. Rio de Janeiro: Ed. UERJ.

Memória, P. R. F. (2012). A Imagem da Mulher na Moda: uma análise das representações dos corpos femininos nas fotografias publicitárias da marca Dolce \& Gabbana (Dissertação de mestrado). Universidade Federal do Ceará, Instituto de Cultura e Arte, Programa de Pós-Graduação em Comunicação, Fortaleza, CE, Brasil. Recuperado de http://www.repositorio.ufc.br/ bitstream/riufc/7865/1/2012-DIS-PRFMEMORIA.pdf

Moscovici, S. (2003). Representações Sociais: investigações em psicologia social (4a ed.). Petrópoles: Vozes.

Mourão, J. S. (2012). Antinomias do feminino: gênero e fiç̧ão em Ressuscitados e Ô de casa! (Dissertação de mestrado). Universidade Federal do Acre, Departamento de Letras: Linguagem e Identidade, Centro de Educação, Letras e Artes, Rio Branco, AC, Brasil. Recuperado de https://drive.google.com/ file/d/OB7JFZNJF-PwOWHIBMzBzby 1 RQS $10 Q V Q 10$ WtqTy $0 \times Q Q /$ view

Oliveira, F. O., \& Werba, G. C. (2013). Representações Sociais. In: Strey, M. N. et al. (Org.). Psicologia Social Contemporânea. Petrópoles: Vozes.

Rother, E. T. (2007). Revisão Sistemática X Revisão Narrativa. Acta Paul Enferm. 20(2),1-2. doi: 10.1590/S010321002007000200001

Scott, J. (1995). Gênero: Uma categoria útil de análise histórica. Educação \& Realidade, 20(2), 71-99. 
Sene, R. A. R. (2017). Identidades de Raça, de Gênero e de Sexualidade nas Aulas de Língua Inglesa na Visão das/os Estudantes (Dissertação de mestrado). Universidade Estadual de Ponta Grossa, Programa de Pós Graduação em Letras, Estudos da Linguagem, Ponta Grossa, PR, Brasil. Recuperado de http://tede2. vepg.br/ispui/bitstream/prefix/1 488/1/Rosana $\% 20$ Aparecida\%20Ribeiro\%20Sene.pdf

Spivak, G. C. (2010). Pode o Subalterno Falar? Belo Horizonte: Editora UFMG.

Shaughnessy, J. J., Zechmeister, E. B., \& Zechmeister, J. S. (2012). Metodologia de pesquisa em psicologia (9a ed.). Porto Alegre: AMGH.

Teixeira, J. M. (2017). Aula 01: Arqueologia do Saber/ Michel Foucault [YouTube]. Recuperado de https:// www.youtube.com/watch? $v=\mathrm{qx} P m O J W 9 A m Q$

Universidade Estadual Paulista, Biblioteca Prof Paulo de Carvalho Mattos (2015). Manual Tipos de Revisão de Literatura [Internet]. Recuperado de http://www. fca.unesp.br/Home/Biblioteca/tipos-de-evisao-deliteratura.pdf 